\title{
Feature-based Dynamic Pricing
}

MAXIME C. COHEN, Google Research

ILAN LOBEL, NYU Stern School of Business

RENATO PAES LEME, Google Research NYC

We consider the problem faced by a firm that receives highly differentiated products in an online fashion and needs to price them in order to sell them to its customer base. Products are described by vectors of features and the market value of each product is linear in the values of the features. The firm does not initially know the values of the different features, but it can learn the values of the features based on whether products were sold at the posted prices in the past. This model is motivated by a question in online advertising, where impressions arrive over time and can be described by vectors of features. We first consider a multi-dimensional version of binary search over polyhedral sets, and show that it has exponential worstcase regret. We then propose a modification of the prior algorithm where uncertainty sets are replaced by their Löwner-John ellipsoids. We show that this algorithm has a worst-case regret that is quadratic in the dimensionality of the feature space and logarithmic in the time horizon.

Additional Key Words and Phrases: Online Learning; Contextual Bandits; Ellipsoid Method; Online Ads; Revenue Management

The full version of this paper is available at http://ssrn.com/abstract=2737045

Permission to make digital or hard copies of part or all of this work for personal or classroom use is granted without fee provided that copies are not made or distributed for profit or commercial advantage, and that copies bear this notice and the full citation on the first page. Copyrights for third-party components of this work must be honored. For all other uses, contact the owner/author(s). Copyright is held by the author/owner(s).

EC '16 July 24-28, 2016, Maastricht, Netherlands

ACM 978-1-4503-3936-0/16/07.

http://dx.doi.org/10.1145/2940716.2940728 